The publication details for this article are as follows:

Torugsa, N., \& O’Donohue, W. 2018. 'Managing knowledge-related barriers to technological innovation through exploitative and explorative organisational strategies', International Journal of Innovation Management, pp. 1-20, DOI: $10.1142 / S 136391961950035 X$ 


\title{
Managing Knowledge-Related Barriers to Technological Innovation through Exploitative and Explorative Organisational Strategies
}

\begin{abstract}
This study uses data from a sample of 31,948 European innovating firms to: examine the impact that knowledge-related barriers to technological innovation have on the link between the level of such innovation and firm performance; and, investigate the role of 'exploitative' and 'explorative' organisational strategies in moderating such impact. Exploitative strategies are measured by the level of organisational innovations, and exploratory strategies are measured by the level of methods for fostering workplace creativity. Using moderated hierarchical regression, the results reveal a negative effect for the interaction between technological innovation and related knowledge constraints on firm performance. They also reveal that the negative interaction effect becomes positive at high levels of organisational innovations and creativity-fostering methods. The study findings thus indicate the need for managers of technologically innovative firms to implement both exploitative and explorative organisational strategies. Doing so could help minimise the negative effects of knowledgerelated barriers to technological innovation, and in turn promote innovation-based competitiveness and business success.
\end{abstract}

Keywords: Technological innovation; knowledge-related barriers; exploitative and explorative strategies; organisational innovations; workplace creativity; firm performance. 


\section{Introduction}

Technological innovation ${ }^{1}$ (i.e., a new or significantly improved product or process as defined in the Oslo Manual; OECD/Eurostat, 2005) is generally accepted as a pathway to competitiveness and business success (Armbruster et al., 2008). However, the journey to innovation-based competitive advantage (on which problems are defined; new ideas are developed, piloted and tested; and new solutions are implemented, problematized, revised, and exploited) is both complex and knowledge dependent, a view that is also widely acknowledged in the literature (Darroch, 2005; Nonaka and Takeuchi, 1995). In highly competitive and rapidly changing business environment, that such a view should dominate is not that surprising given the crucial role knowledge resources have been shown to play in the generation of innovation-driven performance benefits (Nonaka, 1994; Nonaka and Takeuchi, 1995; Torugsa et al., 2016).

The knowledge dependent nature of innovation-based competitiveness means that a firm must be able to capture relevant knowledge within the firm, and leverage such knowledge for the creation and acquisition of new knowledge (Darroch, 2005;

OECD/Eurostat, 2005; Quintane et al., 2011). Hence, the challenge for technologically innovative firms is to develop a capacity for: facilitating the development of existing knowledge; supporting workplace creativity for the creation of new knowledge; developing innovative methods for organising work, decision-making and managing inter-firm collaborations; and, successfully exploiting and maximising the returns from technological innovation (Grant, 2002; He and Wong, 2004; Torugsa et al., 2016). The extent of this challenge is reflected in published empirical evidence showing that a perceived lack of the ability to overcome knowledge factors hampering technological innovation is often seen by

\footnotetext{
${ }^{1}$ The term 'technological' does not necessarily involve the use of high-technology plant and equipment (OECD/Eurostat, 2005).
} 
firms as one of the main barriers to achieving innovation-based competitive advantage (Ballot et al., 2014; D'Este et al., 2012). Despite this evidence, there is little large-scale empirical research to date explicitly investigating the impact of organisational strategies aimed at overcoming knowledge constraints to successful technological innovation. This represents a gap in the literature which this study addresses.

The purpose of this large-scale empirically-based study is to investigate the role of the two specific types of organisational strategies - exploitative (measured by the level of organisational innovations) and explorative (measured by the level of methods for fostering workplace creativity) - in moderating the impact of knowledge constraints on the link between technological innovation and firm performance. Using data from a sample of 31,948 technologically innovative firms that responded to the European Community Innovation Survey (CIS) 2010, the study findings highlight the critical role that such organisational strategies can play in assisting firms to circumvent or overcome the innovation-related barriers to success.

The paper is organised as follows. The next section briefly reviews the relevant literature and develops research hypotheses. This is followed by a discussion of the data and method used. Then, the analysis and results are presented. The study's contributions, limitations and directions for future research are discussed in the last section.

\section{Literature Review and Hypotheses}

\section{Complexity of improving performance through technological innovation: a knowledge- related barrier perspective}

Nonaka (1994) identifies knowledge - in terms of creation, integration and utilisation - as the core element in successful technological innovation, an idea for which there is now broad support in the literature. The knowledge-based view of the firm reflects this idea and makes 
knowledge resources fundamental in the successful development of products (goods or services) and processes (Grant, 1996). In other words, enhanced organisational competitiveness and superior performance through technological innovation in product and process is inherently dependent on the quality and quantity of knowledge resources a firm has. Where a firm has the requisite knowledge resources, the positive association between technological innovation and firm performance is long established (Darroch, 2005; Donate and Sánchez de Pablo, 2015; Gopalakrishnan and Bierly, 2001; Grant, 1996; Lee et al., 2013; Lopez-Nicola and Merono-Cerdan, 2011; Nonaka, 1994; Quintane et al., 2011).

Knowledge resources for technological innovation can be defined as falling under one of two employee-related categories: 'tacit' knowledge, which is rich experience-based knowledge internalised by an individual employee through observation, imitation and practice; and, 'explicit' knowledge, which is codified and formalised knowledge available to an individual employee in the form of written guidelines or policies (Nonaka, 1994; Nonaka and Takeuchi, 1995; Polanyi, 1966). Complexity in knowledge resources derives from the possibility that each of these two types of knowledge comprises at least four components: 'know-why' (i.e., an employee's understanding of the principles underlying innovation, gained through learning-by-studying); 'know-what' (i.e., an employee's appreciation of the kinds of innovation that can be implemented, acquired through learning-by-using); 'knowhow' (i.e., an employee's understanding of the generating procedures that constitute innovation, developed through learning-by-doing); and, 'know-who' (exchanging knowledge for innovation with partners, obtained through learning-by-collaborating) (Garud, 1997; Johnson et al., 2002).

Where competitive advantage through successful technological innovation is the goal, management's primary task is the creation of effective coordination mechanisms and associated organisational strategies for the creation, utilisation and exploitation of the 
complex assortment of knowledge resources (Grant, 1996). However, simply stating it in this way understates the difficulty of the task.

As suggested earlier, the path to successful technological innovation is often complicated, unstructured and disorderly in nature, with simultaneous occurrence of multiple development and implementation options, and overlap in the sequence of problem identification, idea generation, information search, problem-solving, result evaluation, and feedback (Gopalakrishnan and Damanpour, 2001; Torugsa and O’Donohue, 2016).

Moreover, technological innovation activities (e.g. in-house and external research and development; acquisition of patents and non-patented inventions and know-how from outside the firm; maintenance of 'cutting edge' facilities through acquisition of machinery, equipment and software; training for innovation; and market research) require a high level of intensity and resource commitment, plus sophisticated management processes, to be successful. Thus the prospect of engaging in a variety of technological innovation activities for the purpose of developing new products and processes can appear quite daunting for many firms, particularly when deficiencies in the required knowledge resources (e.g. qualified personnel, information on technology and markets, suitable partners for innovation) and organisational systems are perceived as barriers (Gopalakrishnan et al., 1999). In such cases, overcoming these barriers can often be seen by such firms as a well-nigh impossible task, thus diminishing a firm's level of motivation to engage in various technological innovation activities, let alone at the level of intensity required to achieve superior performance and competitive advantage. Research (e.g. Ballot et al., 2014; D'Este et al., 2012) also shows that the more intensive the technological innovation (i.e. the greater variety of technological innovation activities), the greater the degree and variety of knowledgerelated barriers a firm has to face in its implementation, and those that cannot manage and 
work effectively around these barriers are less likely to achieve a successful business outcome.

In line with the above discussion, we argue that although high level of technological innovation is likely to increase business success, its interaction with the knowledge-related barriers involved in such innovation may possibly result in a dampening effect on the firm's performance. Therefore, this study proposes:

Hypothesis 1: The positive association between technological innovation and firm performance is negatively moderated by knowledge-related barriers to innovation.

\section{Organisational strategies for overcoming knowledge-related barriers to technological innovation}

Given the complexity of the knowledge-innovation relationship, the ability to process knowledge efficiently is not in itself sufficient to increase knowledge resources or guarantee successful innovation (Lopez-Nicola and Merono-Cerdan, 2011). It is well-established in the literature that more is required, that is, effective organisational strategies for creating, enhancing and exploiting knowledge resources are essential for firms seeking competitive advantage through intensive technological innovation activities (Darroch and McNaughton, 2002; Donate and Guadamillas, 2011; Oliva, 2014). Such organisational strategies can be broadly classified by aim into two types: 'exploitative' and 'explorative' (Donate and Guadamillas, 2011; Grant, 2002; March, 1991).

Exploitative strategies emphasise effective knowledge application (i.e. through implementing various types of organisational innovations); aim at leveraging existing knowledge through the transfer, sharing and utilisation of knowledge; and potentially help reduce the degree to which a technological innovation is difficult to implement. In contrast, explorative strategies emphasise knowledge generation (i.e. through deploying various 
methods for fostering workplace creativity), and aim at creating new knowledge at the individual, collective and organisational levels (He and Wong, 2004; Grant, 2002; March, 1991). While differing in aim, both types of organisational strategies have been shown to value-add in the development of new products and processes, and are considered prerequisite for overcoming the knowledge-related barriers involved in intensive technological innovation (Darroch and McNaughton, 2002; Lee et al., 2013; Grant, 1996; Moustaghfir and Schiuma, 2013; Nonaka, 1991; Nonaka and Takeuchi, 1995). The two types of organisational strategies are outlined separately below.

\section{Exploitative strategies through implementing organisational innovations}

The strategic value of exploitative organisational strategies in the pursuit of competitive advantage rests in their utility as mechanisms for maximising the value of existing firm knowledge through the creation and implementation of organisational innovations, i.e. new organisational methods or new forms of workplace organisation (Armbruster et al., 2008; Damanpour, 1987; OECD/Eurostat, 2005). Research studies show that particular types of organisational innovation - such as the new systems of: work responsibilities, teamwork, decentralisation, training, and quality management - can directly improve the quality of a firm's existing knowledge resources (Armbruster et al., 2008; Ballot et al., 2014). Research also indicates that embracing exploitative strategies through organisational innovation can stimulate a firm's capacity for technological innovation. This is because the introduction of new products or processes (i.e. technological innovations) requires changes in organisational methods, managerial systems or working concepts to help facilitate intra-firm diffusion of organisational learning, promote the use of knowledge and technologies, and support knowledge accumulation and integration (Ballot et al., 2014; Damanpour et al., 1989; Sapprasert and Clausen, 2012). Potential complementarity between organisational and 
technological innovations means that such exploitative strategies are likely to improve the efficiency with which existing knowledge resources for technological innovation can be utilised effectively, contributing positively to firm performance (Armbruster et al., 2008; Damanpour et al., 1989; Greenan, 2003). This reasoning leads to the following hypothesis: Hypothesis 2: The negative effect of the interaction between knowledge-related barriers and technological innovation on firm performance is positively moderated by exploitative (organisational innovation) strategies.

\section{Explorative strategies through deploying creativity-fostering methods}

The strategic value of explorative organisational strategies rests in their contribution to an organisational culture that stimulates and fosters workplace creativity, i.e. a climate that promotes new and useful ways of thinking, encourages individual and collective motivation and enthusiasm, and rejuvenates organisational change and learning (Amabile, 1988; Montag et al., 2012; Shin et al., 2012). A firm's capacity for exploring and capitalising on new knowledge for technological innovation is reflected in the array of methods deployed for fostering workplace creativity (Borghini, 2005). Such methods could include: using brainstorming sessions and multidisciplinary functional work teams; providing (financial and non-financial) incentives to promote idea generation; and enabling development of new ideas and innovations through provision of adequate resources and training (Shin et al., 2012). The greater the level of creativity-fostering methods, the more likely the staff are motivated and empowered to initiate changes and adopt new perspectives. This has the potential to promote and reinforce the innovation-performance connection. On this basis, explorative organisation strategies play a key role in the generation of new knowledge and degree of knowledge resources required for intensive technological innovation activities. This reasoning leads to the following hypothesis: 
Hypothesis 3: The negative effect of the interaction between knowledge-related barriers and technological innovation on firm performance is positively moderated by explorative (workplace creativity) strategies.

Figure 1 presents the proposed hypothesised model in this study. This model shows how exploitative and explorative strategies might moderate the effect of the interaction between knowledge-related barriers and technological innovation on firm performance.

\section{Insert Figure 1}

\section{Data and Method}

This study uses data from the European Community Innovation Survey (CIS) 2010, covering 18 European countries (i.e., Belgium, France, Luxembourg, Norway, Sweden, Italy, Portugal, Czech Republic, Estonia, Hungary, Slovenia, Slovak Republic, Ireland, Bulgaria, Lithuania, Latvia, Romania and Cyprus $^{2}$ ) and accessed in the Eurostat's Safe Centre in Luxembourg. The survey reference period was from 2008 to 2010 and the target respondent was the senior manager or owner. The survey was carried out by the national statistical office of each participating European country and coordinated by Eurostat. In order to avoid potential data analysis problems in relation to sample bias and comparability, Eurostat data are collected and organised using: a standard core questionnaire, along with an accompanying set of definitions and methodological recommendations based on the Oslo Manual (OECD/Eurostat, 2005); and, stratification of samples (by firm size and sector) to ensure representativeness. Sampling and non-sampling errors were corrected using weighting

\footnotetext{
${ }^{2}$ The CIS 2010 data made available at the Eurostat's Safe Centre also covered Germany, Spain, Finland and the Netherlands. However, data from these four countries were excluded from this study because of missing information on knowledge-related barriers, workplace support for creativity, or markets of selling innovative products.
} 
procedures across innovation and related measures to provide a comparable and consistent data set for all European countries.

The survey received 94,315 responses from firms in the manufacturing and service sectors $^{3}$, of which $32,025(34 \%)$ reported the introduction of one or more product ${ }^{4}$ or process $^{5}$ innovations (i.e., technological innovations) and were asked the questions about knowledge factors hampering such innovations. After responses with missing data were eliminated, a total of 31,948 technologically innovative firms (i.e. those having technological innovation output) remained for analysis in this study.

Due to the cross-sectional, self-reported nature of the CIS 2010 data, common method variance may cause measurement error and bias the estimates. To test whether this was a problem, Harman's single-factor test was performed (Podsakoff et al., 2003). All of the variables included in the study's analyses were entered into an unrotated principal component analysis. The analysis revealed the presence of four distant factors with eigenvalues greater than 1 . The four factors together accounted for $58 \%$ of the total variance, and the largest factor did not account for a majority of the variance (22\%). As no single general factor is apparent, common method variance is adjudged as not a major concern in this study.

\section{Variables}

The full CIS 2010 questionnaire is available at http://ec.europa.eu/eurostat/documents/203647/203701/CIS_Survey_form_2010.pdf/b9f2c70 e-0c46-4f82-abeb-c7661f1f2166. Exact quotations are provided below for relevant survey questions.

\footnotetext{
${ }^{3}$ The survey also received responses from firms in the mining and industrial sectors. However, as these two sectors were dominated by large firms, and many countries in the sample had no firms in these sectors, these data were excluded from the analysis.

${ }^{4}$ New or significantly improved goods or services.

${ }^{5} \mathrm{New}$ or significantly improved production process, distribution methods or supporting activity.
} 
The dependent variable is firm performance measured by the logarithm of the firm's total turnover, defined as "market sales of goods and services", over the final year (2010) covered by the survey [Turnover].

The independent variable is the level of technological innovation [TI], measured as the sum of the eight types of innovation activities for new products or processes implemented during the three-year observation period (2008-2010): "in-house R\&D”, “external R\&D”, "acquisition of machinery, equipment and software", "acquisition of external knowledge (e.g. purchase or licensing of patents and non-patented inventions, know-how, and other types of knowledge from other enterprises or organisations)", "training for innovative activities", "market introduction of innovations e.g. market research and launch advertising", "design", and "other (e.g. feasibility studies, testing, routine software development, tooling up, industrial engineering, etc.)". The TI variable therefore has a scale from 0 (no activity implemented) to 8 (all activities of technological innovation implemented).

The three moderating variables are: level of knowledge-related barriers to technological innovation [KB]; level of exploitative 'organisational innovation' [OI] strategies; and level of explorative 'workplace creativity' [WP] startegies. These variables were measured over the three years covered by the survey (2008-2010).

With regard to the moderating variable for knowledge-related barriers, respondents were asked to indicate, using a four-point scale $(0=$ "factor not experienced", 1 = "low", $2=$ "medium", and 3 = "high"), the importance of four specific knowledge factors in hampering their product or process innovation activities: "lack of qualified personnel", "lack of information on technology", "lack of information on markets", and "difficulty in finding cooperation partners for innovation". The values for each of these four factors were summed with the aggregate values ranging from 0 to 12 in order to form the KB variable. 
The moderating variable for exploitative strategies was measured as the sum of the three types of organisational innovations (OI) reported by responding firms: "new business practices for organising procedures (i.e. supply chain management, business reengineering, knowledge management, lean production, quality management, etc.)"; "new methods of organising work responsibilities and decision making (i.e. first use of a new system of employee responsibilities, team work, decentralisation, integration or de-integration of departments, education/training systems, etc.)"; and "new methods of organising external relations with other firms or public institutions (i.e. first use of alliances, partnerships, outsourcing or sub-contracting, etc.)". The OI variable thus has a scale from 0 (no exploitative strategy) to 3 (all types of exploitative strategies implemented).

The moderating variable for explorative strategies was measured as the sum of the six types of creativity-fostering methods (WP) reported by responding firms as "successful in producing new ideas or increasing creativity". These methods include: "brainstorming sessions"; "multidisciplinary or cross-functional work teams"; "job rotation of staff to different departments or other parts of your enterprise group"; "financial incentives for employees to develop new ideas"; "non-financial incentives for employees to develop new ideas, such as free time, public recognition, more interesting work, etc."; and "training employees on how to develop new ideas or creativity". The WC variable therefore has a scale from 0 (no successful explorative strategy) to 6 (all explorative strategies deployed were successful).

Several control variables ${ }^{6}$ were included to account for other factors that could affect the estimation results. First, as firms that are part of a larger business could draw on knowledge assets from their business group to increase their innovation capacity and

\footnotetext{
${ }^{6}$ Firm size (measured by the natural logarithm of the number of employees) was not included as a control variable due to its high correlation with the dependent variable for firm performance $(r>0.8)$. Including firm size would result in multicollinearity problems and misleading conclusions.
} 
performance outcomes (Torugsa and Arundel, 2013), a (0/1) dummy variable [Group] for whether a firm is part of a larger business was included. Second, as internationalised firms could be more aware of knowledge gaps and better able to find ways for improving their market sales than firms that only operate domestically, the models included a (0/1) dummy variable [IntMk] for internationalisation via exporting, coded as 1 if the respondent reported "other European Union (EU), EFTA, or EU candidate countries" or "all other countries" as a market of selling goods and/or services, and 0 if only "local/regional within your country" and/or "national (other regions of your country)" was reported. Third, the data used in this study includes firms from six broad sectors (i.e., high-tech manufacturing, medium-high-tech manufacturing, medium-low-tech manufacturing, low-tech manufacturing, knowledge intensive services (KIS), and less-KIS ${ }^{7}$ ), five sector dummies were included to control for heterogeneity in the sector's technological opportunities. Finally, to control for national differences and thus unobserved national factors, seventeen country dummies were also included.

\section{Analysis and Results}

The means, standard deviations and correlations among the analysed variables are presented in Table 1. The estimated correlations between variables were well below 0.7 , suggesting discriminant validity for the study constructs. To test the research hypotheses, the approach to testing moderation recommended by Baron and Kenny (1986) was employed. Specifically, this study constructed separate variables for the predictor (TI), moderators (KB, OI and WC), two-way interaction term $(\mathrm{TI} \times \mathrm{KB})$, and three-way interaction terms $(\mathrm{TI} \times \mathrm{KB} \times \mathrm{OI}$, and $\mathrm{TI} \times \mathrm{KB} \times \mathrm{WC}$ ). Following the suggestion of Aiken and West (1991), both the predictor and

\footnotetext{
${ }^{7}$ These sectors are grouped based on the Eurostat's technological intensity classification (NACE Revision 2) see http://ec.europa.eu/eurostat/cache/metadata/Annexes/htec_esms_an3.pdf
} 
moderator variables were mean-centered prior to creating interaction terms to reduce the potential problem of multicollinearity between the main effects and their interactions. To prove moderating effects, as asserted by Baron and Kenny (1986), the interaction term must be significant. There could also be significant main effects for the predictor and moderator variables but these effects are not directly relevant conceptually to testing the moderation hypothesis.

Insert Table 1

This study employed a moderated hierarchical ordinary least squares (OLS) regression analysis, and the results are presented in Table 2. Model 1 included only control variables and explained $36.4 \%$ of the variance in firm performance $(F=763.24, p=0.000)$. Model 2 added the main effect of TI and explained $38.7 \%$ of the variance in firm performance $(\mathrm{F}=758.27, \mathrm{p}=0.000)$. The result showed that without considering other explanatory variables, TI had a main positive effect on firm performance. Model 3 added the main effects of $\mathrm{KB}$, OI and $\mathrm{WC}\left(\mathrm{F}=746.16, \mathrm{p}=0.000\right.$, adjusted $\left.\mathrm{R}^{2}=39.5 \%\right)$. The results revealed that without considering the interaction effects, $\mathrm{KB}$ had a main negative effect on firm performance while a main positive effect was observed for both OI and WC. The twoway interaction term of TI $\times \mathrm{KB}$ was entered in Model $4\left(\mathrm{~F}=721.29, \mathrm{p}=0.000\right.$, adjusted $\mathrm{R}^{2}=$ $39.6 \%$ ). Model 5 added the three-way interaction terms of $\mathrm{TI} \times \mathrm{KB} \times \mathrm{OI}$ and $\mathrm{TI} \times \mathrm{KB} \times \mathrm{WC}$. This model was significant $(\mathrm{F}=688.66, \mathrm{p}=0.000)$ and explained $41 \%$ of the variance in firm performance. It also represented a significant improvement over other models as indicated by the lowest AIC and BIC values. Model 5 is the final full model used for hypothesis testing. The variance inflation factor (VIF) values for this model's regression coefficients ranged from 1.15 to 2.67 and thus were well below the recommended cut-off of 10 (Mason and 
Perreault, 1991), suggesting that multicollinearity did not affect the weights of the hypothesised variables.

\section{Insert Table 2}

As shown in Model 5 (Table 2), there was a positive and significant association between TI and firm performance $(\beta=0.156, \mathrm{p}<0.001)$. The coefficient for the TI $\times \mathrm{KB}$ interaction term was negative and significant $(\beta=-0.061, \mathrm{p}<0.001)$, which indicates that $\mathrm{KB}$ decreased the benefits of TI for firm performance, thereby supporting Hypothesis 1 . The coefficients for both the $\mathrm{TI} \times \mathrm{KB} \times \mathrm{OI}(\beta=0.050)$ and $\mathrm{TI} \times \mathrm{KB} \times \mathrm{WC}(\beta=0.080)$ interaction terms were positive and significant $(\mathrm{p}<0.001)$. These results suggest that the negative effect of $\mathrm{KB}$ on firm performance declined at high levels of organisational innovation (OI) and workplace support for creativity (WC) compared to low levels of OI and WC, thereby supporting Hypotheses 2 and 3.

In order to explore the nature of these interactions further, simple slopes were calculated and the interactions were graphed. Figure 2 illustrates the effect of TI on firm performance moderated by KB, showing that the TI-performance association was negative and significant at high levels of $\mathrm{KB}$ (simple slope $=-0.28, \mathrm{p}<0.001)$ but this association declined and became insignificant at low levels of KB (simple slope $=0.04, \mathrm{p}>0.1)$. This result provides further support for Hypothesis 1 . The effects of the TI $\times \mathrm{KB}$ interaction on firm performance moderated by OI and WC were shown in Figures 3 and 4 respectively. Based on these figures, the $\mathrm{TI} \times \mathrm{KB}$ effect on firm performance was positive and significant at high levels of OI (simple slope $=0.32, \mathrm{p}<0.001)$ and WC (simple slope $=0.38, \mathrm{p}<0.001)$, but this effect declined and became insignificant at low levels of OI and WC (each with simple slope $=0.03, \mathrm{p}>0.1$, hence providing further support for Hypotheses 2 and 3. 
Insert Figure 2

Insert Figure 3

Insert Figure 4

\section{Discussion and Conclusions}

In this study, we use very large-scale survey data at the firm level to investigate the role of 'exploitative' (organisational innovation) and 'explorative' (workplace creativity) strategies in moderating the interaction effect of technological innovation and knowledge-related barriers on firm performance. Using moderated hierarchical OLS regression, the study findings unveil that the effect of technological innovation on firm performance was dampened by the knowledge-related barriers involved, but such a dampening interaction effect became positive at high levels of organisational innovations and creativity-fostering methods. These results suggest that to achieve superior performance, firms need to consider not only the intensity or breadth of their product and process innovation activities, but also the exploitative and explorative organisational strategies that can be used to circumvent and overcome knowledge-related barriers to technological innovation (Gopalakrishnan et al., 1999; Ballot et al., 2014). Exploitative and explorative startegies in the forms of organisational innovation and workplace creativity appear to underpin technological innovation activities at the level of intensity required for competitive success (Darroch and McNaughton, 2002; Lee et al., 2013; Grant, 1996; Moustaghfir and Schiuma, 2013; Nonaka, 1991; Nonaka and Takeuchi, 1995).

The evidence presented in this study clearly points to the importance of both the implementation of organisational innovations and the deployment of methods for fostering workplace creativity as critical contingencies in determining the effective development and 
utilisation of a firm's knowledge resources for technological innovation. Linking implementation of a technological innovation to exploitative and explorative strategies in this way would help ensure that a firm's technological innovation efforts contribute positively to superior returns. The findings of this study therefore carry significant implications for research and practice.

\section{Implications for research}

The novel contribution of this study is twofold. First, the study findings stress the importance of both exploitative (organisational innovation) and explorative (workplace creativity) startegies in enhancing a firm's capacity to overcome or circumvent knowledge-related barriers to technological innovation. Second, the findings highlight the essential role of such organisational strategies in facilitating the creation of new knowledge resources and their integration and application with existing knowledge resources for new product/process development that underpin innovation-based competitiveness and business success. These findings are in line with a knowledge-based view of the firm (Grant, 1996) and lend support to the argument in the literature that a firm can create and realise advantages from its innovation production only when its knowledge resources are effectively managed and supported by changes in organisational procedures and practices aimed at improving the internal flows and use of information and fostering workplace creativity (e.g. Darroch and McNaughton, 2002; Donate and Guadamillas, 2011; Lee et al., 2013; Moustaghfir and Schiuma, 2013; Nonaka, 1991; Nonaka and Takeuchi, 1995; OECD/Eurostat, 2005).

\section{Implications for practice}

The study findings indicate the need for managers, wishing to minimise the negative effects of knowledge-related barriers to technological innovation and maximise innovation benefits, 
to develop and execute organisational strategies that support the application and generation of knowledge required to underpin successful implementation of technological innovation. Such strategies include: the changes in business practices and structures, managerial systems and working concepts aimed at improving the quality and efficiency of work; as well as, the greater use of brainstorming sessions, multidisciplinary or cross-functional work teams, financial and non-financial rewards and incentives for creativity, and creativity skills training and development for employees. In so doing, a firm's capacity to exploit existing knowledge, explore and create new knowledge, at the individual and collective level, for the development of product and process innovations that might serve as a basis for competitive advantage can be enhanced.

\section{Limitations and directions for future research}

This study has some important limitations that could be examined in future research. First, it can be argued that the data on organisational innovations and methods for fostering workplace creativity are not sufficiently detailed to allow us to precisely measure the exploitative and exploratory strategies. Furthermore, due to data limitations, potential key mechanisms in knowledge exploitation and exploration, such as organisational culture and leadership, cannot be identified and tested. As a consequence, the practical relevance of the study findings can be limited, and future research should aim to provide a more fine-grained explanation of the relationships proposed in this study. For instance, future studies examining the organisational learning mechanisms underlying the management of knowledge-related barriers to innovation could yield high value to practitioners and scholars alike.

Second, the moderated regression analysis used in this study is based on the assumption of net effects and symmetric relationships. However, different specific exploitative and explorative strategies and other factors could be aligned in multiple ways to 
circumvent knowledge factors hampering technological innovation, and in turn spur innovation-based competitiveness and business success. Future research employing settheoretic methods to explore different combinations and asymmetries in the relationship among these factors could produce more robust findings and develop a more a nuanced picture of the way forward in the face of knowledge-related barriers to technological innovation (see Torugsa and O’Donohue, 2016).

Third, the findings are limited to firms within Europe and by the use of crosssectional data. Further examination of the study models in non-European countries over a longer time period can help reveal more time- and economy-related effects, thereby allowing for broader generalizability in findings. Finally, although differences associated with the degree of technological innovation (radical and incremental) go beyond the scope of this study, it would be of great value for future research to examine these differences to better understand how firms can benefit from their innovation efforts through exploitative and explorative organisational startegies.

\section{References}

Aiken, L.S. and West S.G. (1991). Multiple Regression: Testing and Interpreting Interactions. Newbury Park, CA: Sage Publications.

Amabile, T.M. (1988). A model of creativity and innovation in organizations. In Staw, B.M. and Cummings, L.L. (Eds.), Research in Organizational Behavior, pp. 123-167. Greenwich, CT: JAI Press.

Armbruster, H., Bikfalvi, A., Kinkel, S. and Lay, G. (2008). Organizational innovation: The challenge of measuring non-technical innovation in large-scale surveys. Technovation, 28 (10), 644-657.

Ballot, G., Fakhfakh, F., Galia, F. and Salter, A. (2015). The fateful triangle: complementarities in performance between product, process and organizational innovation in France and the UK. Research Policy, 44(1), 217-232.

Baron, R.M. and Kenny, D.A. (1986). The moderator-mediator variable distinction in social psychological research: Conceptual, strategic and statistical considerations. Journal of Personality and Social Psychology, 51(6), 1173-1182.

Borghini, S. (2005). Organizational creativity: Breaking equilibrium and order to innovate. Journal of Knowledge Management, 9(4), 19-33. 
D’Este, P., Iammarino, S., Savona, M. and von Tunzelmann, N. (2012). What hampers innovation? Revealed barriers versus deterring barriers. Research Policy, 41(2), 482488.

Damanpour, F. (1987). The adoption of technological, administrative and ancillary innovations: Impact of organizational factors. Journal of Management, 13(4), 675688.

Damanpour, F., Szabat, K.A. and Evan, W.M. (1989). The relationship between types of innovation and organizational performance. Journal of Management Studies, 26(6), $587-601$.

Darroch, J. (2005). Knowledge management, innovation and firm performance. Journal of Knowledge Management, 9(3), 101-115.

Darroch, J. and McNaughton, R. (2002). Examining the link between knowledge management practice and types of innovation. Journal of Intellectual Capital, 3(3), 210-222.

Donate, M. J. and Guadamillas, F. (2011). Organizational factors to support knowledge management. Journal of Knowledge Management, 15(6), 890-914.

Donate, M.J. and Sánchez de Pablo, J.D. (2015). The role of knowledge-oriented leadership in knowledge management practices and innovation. Journal of Business Research, 68(2), 360-370.

Garud, R. (1997). On the distinction between know-how, know-why, and know-what, in Huff, A. and Walsh, J. (Eds.), Advances in Strategic Management, pp. 81-101, Greenwich, CT: JAI Press.

Gopalakrishnan, S. and Bierly, P. (2001). Analyzing innovation adoption using a knowledgebased approach. Journal of Engineering and Technology Management, 18(2), 107130.

Gopalakrishnan, S., Bierly, P. and Kessler, E. (1999). A reexamination of product and process innovations using a knowledge-based view. Journal of High Technology Management Research, 10(1), 147-166.

Gopalakrishnan, F. and Damanpour, S. (2001). The dynamics of the adoption of product and process innovations in organizations. Journal of Management Studies, 38(1), 45-65.

Grant, R.M. (1996). Toward a knowledge-based theory of the firm. Strategic Management Journal, 17, 109-122.

Grant, R.M. (2002). Contemporary Strategy Analysis. Concepts, Techniques and Applications ( $4^{\text {th }}$ Ed.), Boston: Blackwell Publishers.

Greenan, N. (2003). Organizational change, technology, employment and skills: An empirical study of French manufacturing. Cambridge Journal of Economics, 27(2), 287-316.

He, Z-L. and Wong, P-K. (2004). Exploration vs exploitation: an empirical test of the ambidexterity hypothesis, Organization Science, 15(4), 481-494.

Johnson, B., Lorenz, E. and Lundvall B-A. (2002). Why all this fuss about codified and tacit knowledge. Industrial and Corporate Change, 11(2), 245-262.

Lee, V-H., Leong, L-Y., Hew, T-S. and Ooi, K-B. (2013). Knowledge management: A key determinant in advancing technological innovation?. Journal of Knowledge Management, 17(6), 848-872.

Lopez-Nicolas, C. and Merono-Cerdan, A.L. (2011). Strategic knowledge management, innovation and performance, International Journal of Information Management, 31(6), 502-509. 
March, J.G. (1991). Exploration and exploitation in organizational learning. Organization Science, 2(1), 71-87.

Mason, C. and Perreault, W. (1991). Collinearity, power, and interpretation of multiple regression analysis. Journal of Marketing Research, 28(3), 268-280.

Montag, T., Maertz, C.P. and Baer. M. (2012). A critical analysis of the workplace creativity criterion space. Journal of Management, 38(4), 1362-1386.

Moustaghfir, K. and Schiuma, G. (2013), Knowledge, learning, and innovation: research and perspectives. Journal of Knowledge Management, 17(4), 495-510.

Nonaka, I. (1991). The knowledge creating company. Harvard Business Review, 69(6), 96104.

Nonaka, I. (1994). A dynamic theory of organizational knowledge creation, Organization Science, 5(1), 14-37.

Nonaka, I. and Takeuchi, H. (1995). The Knowledge Creating Company: How Japanese Companies Create the Dynamics of Innovation, New York: Oxford University Press.

OECD/Eurostat (2005), OECD Oslo Manual: Guidelines for Collecting and Interpreting Innovation Data ( $3^{\text {rd }}$ Ed.), Paris: OECD Publishing.

Oliva, F.L. (2014). Knowledge management barriers, practices and maturity model. Journal of Knowledge Management, 18(6), 1053-1074.

Podsakoff, P.M., MacKenzie, S.M., Lee, J. and Podsakoff, N.P. (2003), Common method variance in behavioral research: A critical review of the literature and recommended remedies. Journal of Applied Psychology, 88(5), 879-903.

Polanyi, M. (1966), The Tacit Dimension, London: Routledge \& Kegan Paul.

Quintane, E., Casselman, R.M., Reiche, B.S. and Nylund, P. (2011). Innovation as a knowledge-based outcome. Journal of Knowledge Management, 15(6), 928-947.

Sapprasert, K. and Clausen, T. (2012). Organizational innovation and its effects. Industrial and Corporate Change, 21(5), 1283-1305.

Shin, S.J., Kim, T.Y., Lee, J.Y. and Bian, L. (2012). Cognitive team diversity and individual team member creativity: A cross-level interaction. Academy of Management Journal, 55(1), 197-212.

Torugsa, N. and Arundel A. (2013). Private-public collaboration and innovation performance: Does training matter?. International Journal of Innovation Management, 17(3), 1-20.

Torugsa, N., Arundel, A. and O'Donohue, W. (2016). Inter-firm collaboration and innovation performance for new-to-market products: The moderating role of technological and skilled knowledge assets, International Journal of Innovation Management, 20(4), 122.

Torugsa, N. and O’Donohue, W. (2016). Progress in innovation and knowledge management research: from incremental to transformative innovation. Journal of Business Research, 69(5), 1610-1614. 
Table 1. Means, standard deviations and correlations $(n=31,948)$

\begin{tabular}{|c|c|c|c|c|c|c|c|c|}
\hline & Mean & S.D. & 1 & 2 & 3 & 4 & 5 & 6 \\
\hline 1. Firm performance $[\log$ of turnover] & 6.860 & 0.864 & & & & & & \\
\hline 2. Technological innovation [TI] & 3.512 & 2.148 & $0.247 * * *$ & & & & & \\
\hline 3. Knowledge-related barriers to innovation $[\mathrm{KB}]$ & 4.351 & 3.029 & $-0.164 * * *$ & $0.145^{* * *}$ & & & & \\
\hline 4. Explorative 'organisational innovation' strategies $[\mathrm{OI}]^{\mathrm{a}}$ & 1.216 & 1.179 & $0.210 * * *$ & $0.314 * * *$ & $0.086^{* * *}$ & & & \\
\hline 5. Explorative 'workplace creativity' strategies [WC] $]^{\mathrm{b}}$ & 1.361 & 1.596 & $0.220 * * *$ & $0.323 * * *$ & $0.051 * * *$ & $0.312 * * *$ & & \\
\hline 6. Being part of a larger business [Group] & 0.483 & 0.499 & $0.507 * * *$ & $0.190 * * *$ & $-0.056 * * *$ & $0.131 * * *$ & $0.194 * * *$ & \\
\hline 7. Internationalisation via exporting [IntMk] & 0.657 & 0.475 & $0.206^{* * *}$ & $0.196 * * *$ & $0.071 * * *$ & $0.051^{* * *}$ & $0.092 * * *$ & $0.172 * * *$ \\
\hline
\end{tabular}

***p $<0.001 .{ }^{a} 41 \%$ of firms reported no organisational innovation. ${ }^{b} 46 \%$ of firms reported no 'successful' workplace support for creativity. 
Table 2. Results of moderated OLS regression models for firm performance $(n=31,948)$

\begin{tabular}{|c|c|c|c|c|c|}
\hline \multirow{2}{*}{ Variable } & \multicolumn{5}{|c|}{ Dependent variable: the logarithm of the firm's total turnover } \\
\hline & Model 1 & Model 2 & Model 3 & Model 4 & Model 5 \\
\hline Group & $\begin{array}{l}0.456^{* * * *} \\
(0.008)\end{array}$ & $\begin{array}{l}0.436 * * * \\
(0.008)\end{array}$ & $\begin{array}{l}0.421 * * * \\
(0.008)\end{array}$ & $\begin{array}{l}0.421 * * * \\
(0.008)\end{array}$ & $\begin{array}{l}0.416 * * * \\
(0.008)\end{array}$ \\
\hline IntMk & $\begin{array}{l}0.127 * * * \\
(0.009)\end{array}$ & $\begin{array}{l}0.103^{* * * *} \\
(0.009)\end{array}$ & $\begin{array}{l}0.101 * * * \\
(0.009)\end{array}$ & $\begin{array}{l}0.101^{* * * *} \\
(0.009)\end{array}$ & $\begin{array}{l}0.101 * * * \\
(0.009)\end{array}$ \\
\hline Sector dummies & (included) & (included) & (included) & (included) & (included) \\
\hline Country dummies & (included) & (included) & (included) & (included) & (included) \\
\hline $\mathrm{TI}$ & & $\begin{array}{l}0.169 * * * \\
(0.002)\end{array}$ & $\begin{array}{l}0.220 * * * \\
(0.002)\end{array}$ & $\begin{array}{l}0.221 * * * \\
(0.002)\end{array}$ & $\begin{array}{l}0.156 * * * \\
(0.002)\end{array}$ \\
\hline $\mathrm{KB}$ & & & $\begin{array}{l}-0.051 * * * \\
(0.001)\end{array}$ & $\begin{array}{l}-0.052 * * * \\
(0.001)\end{array}$ & $\begin{array}{l}-0.099 * * * \\
(0.002)\end{array}$ \\
\hline OI & & & $\begin{array}{l}0.040 * * * \\
(0.006)\end{array}$ & $\begin{array}{l}0.039 * * * \\
(0.006)\end{array}$ & $\begin{array}{l}0.030 * * * \\
(0.006)\end{array}$ \\
\hline WC & & & $\begin{array}{l}0.070 * * * \\
(0.005)\end{array}$ & $\begin{array}{l}0.069^{* * * *} \\
(0.005)\end{array}$ & $\begin{array}{l}0.063 * * * \\
(0.005)\end{array}$ \\
\hline TI x KB & & & & $\begin{array}{l}-0.037 * * * \\
(0.001)\end{array}$ & $\begin{array}{l}-0.061 * * * \\
(0.001)\end{array}$ \\
\hline TI $x \mathrm{~KB} \times \mathrm{OI}$ & & & & & $\begin{array}{l}0.050 * * * \\
(0.001)\end{array}$ \\
\hline TI $x$ KB x WC & & & & & $\begin{array}{l}0.080 * * * \\
(0.001)\end{array}$ \\
\hline Degree of freedom (df) & 24 & 25 & 28 & 29 & 31 \\
\hline F value & 763.24 & 758.27 & 746.16 & 721.29 & 688.66 \\
\hline Prob $>$ F & 0.000 & 0.000 & 0.000 & 0.000 & 0.000 \\
\hline Adjusted $\mathrm{R}^{2}$ & 0.364 & 0.387 & 0.395 & 0.396 & 0.410 \\
\hline AIC & 66890.00 & 65712.54 & 65299.71 & 65286.34 & 65029.90 \\
\hline $\mathrm{BIC}$ & 67099.30 & 65930.21 & 65542.50 & 65537.50 & 65297.80 \\
\hline
\end{tabular}

$* * * \mathrm{p}<0.001$. The coefficients reported are standardized (beta or $\beta$ ). Standard errors are in parentheses. 
Figure 1. The study's hypothesised model

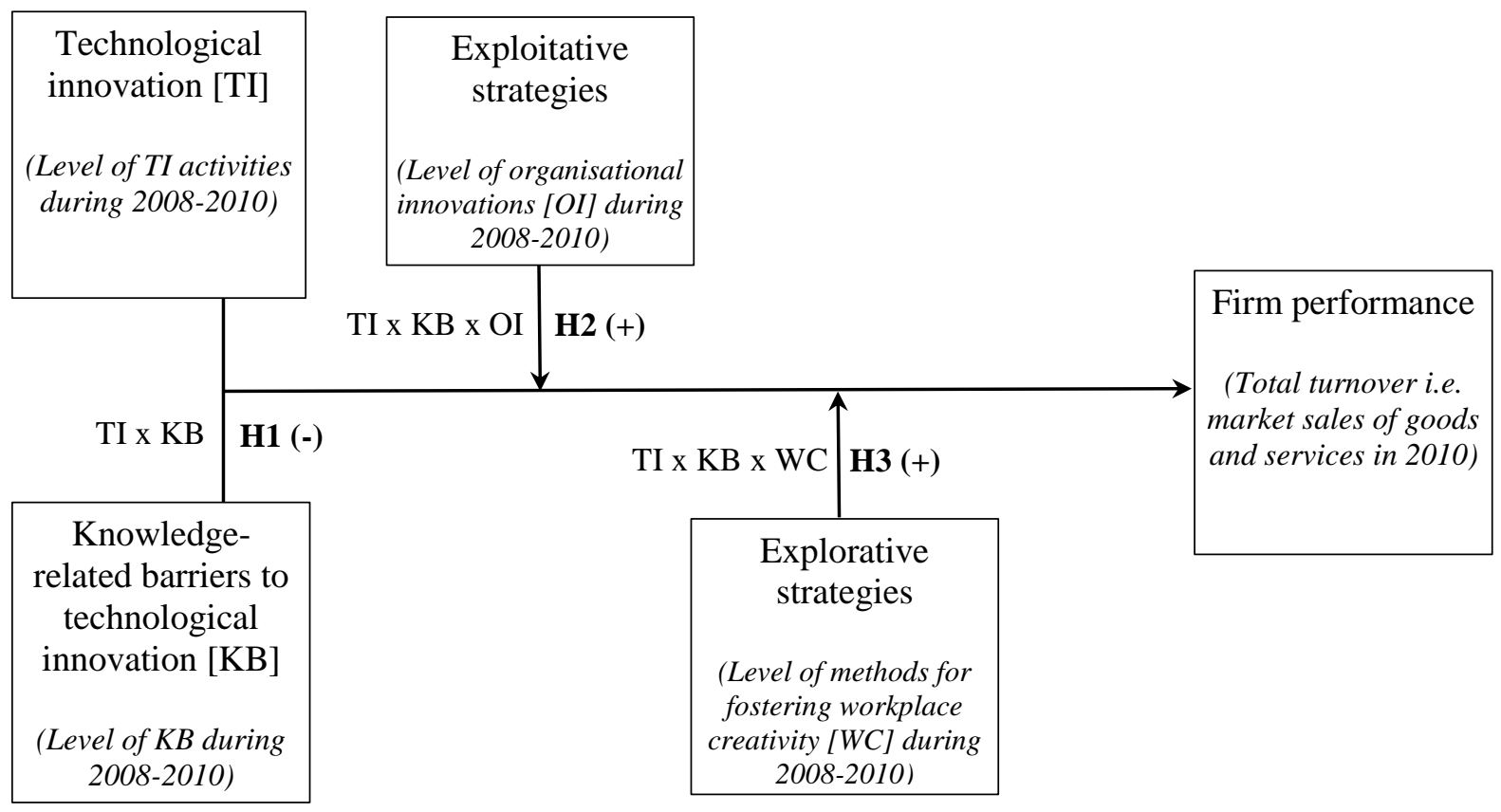


Figure 2. Effect of TI on firm performance moderated by KB

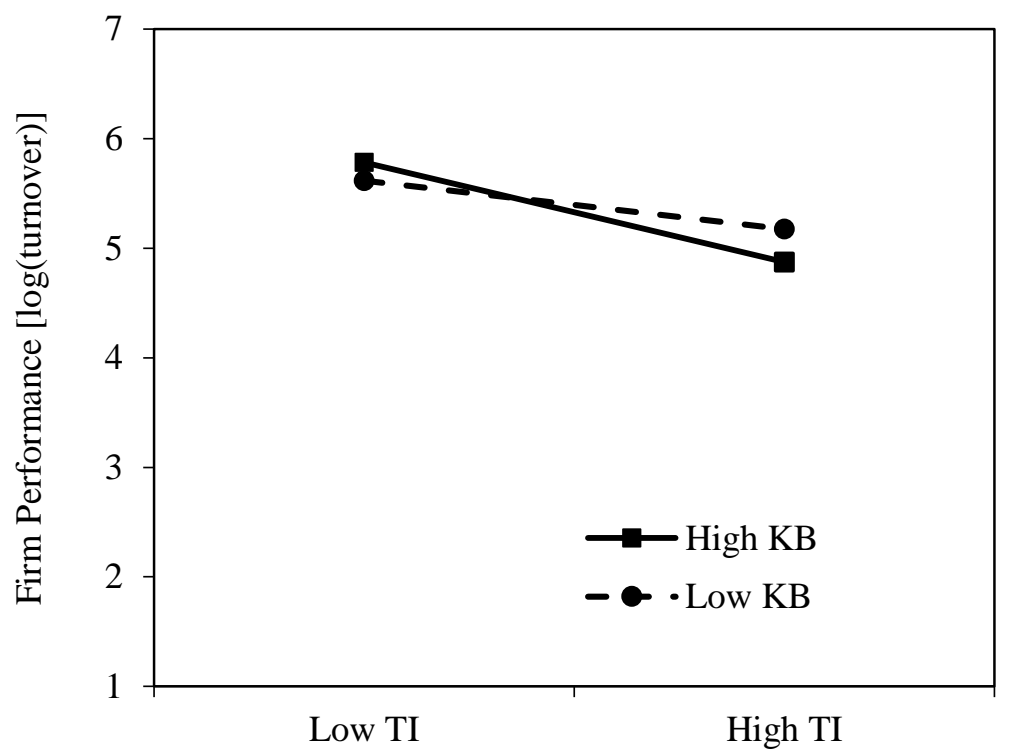


Figure 3. Effect of TI $\times \mathrm{KB}$ on firm performance moderated by OI

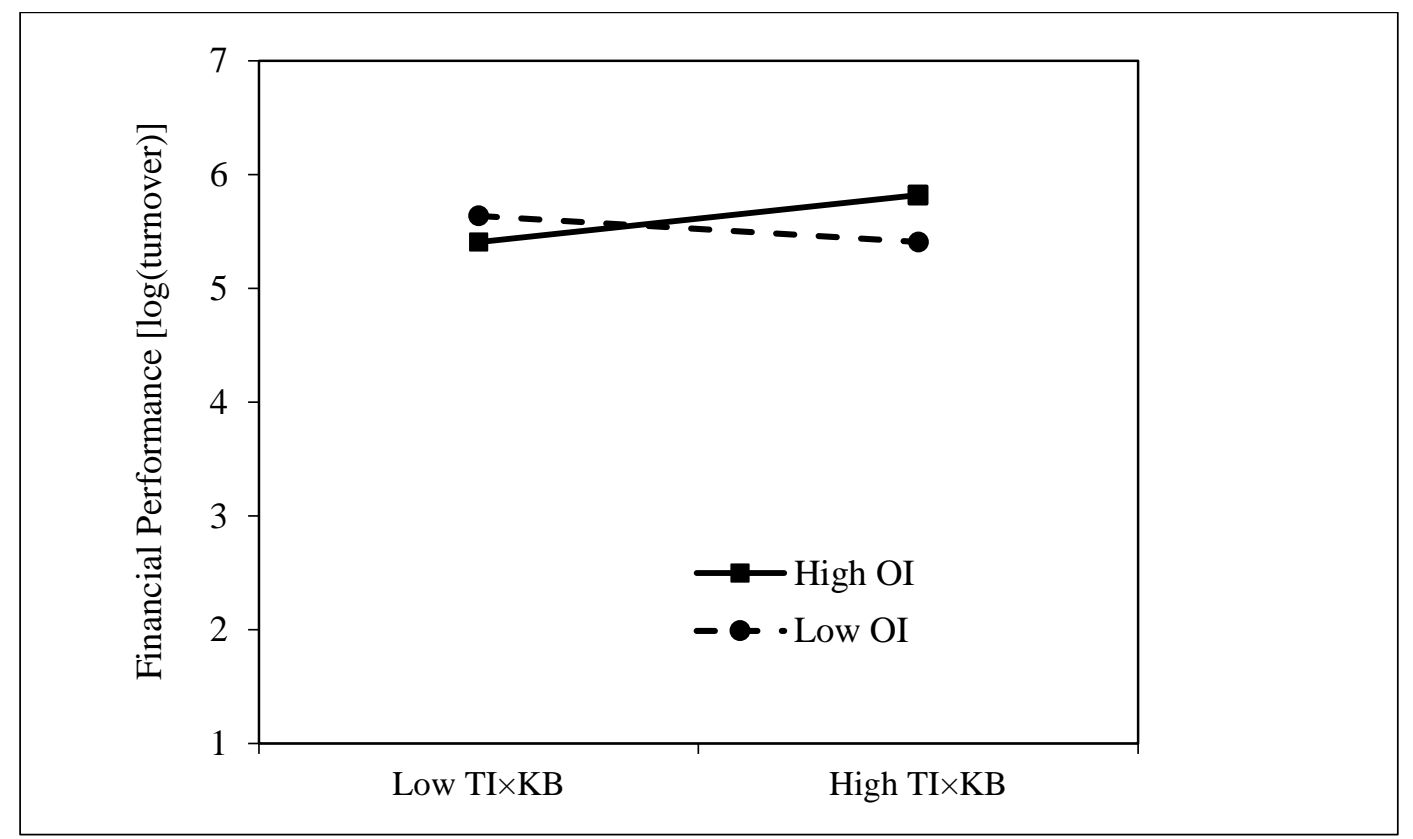


Figure 4. Effect of $\mathrm{TI} \times \mathrm{KB}$ on firm performance moderated by WC

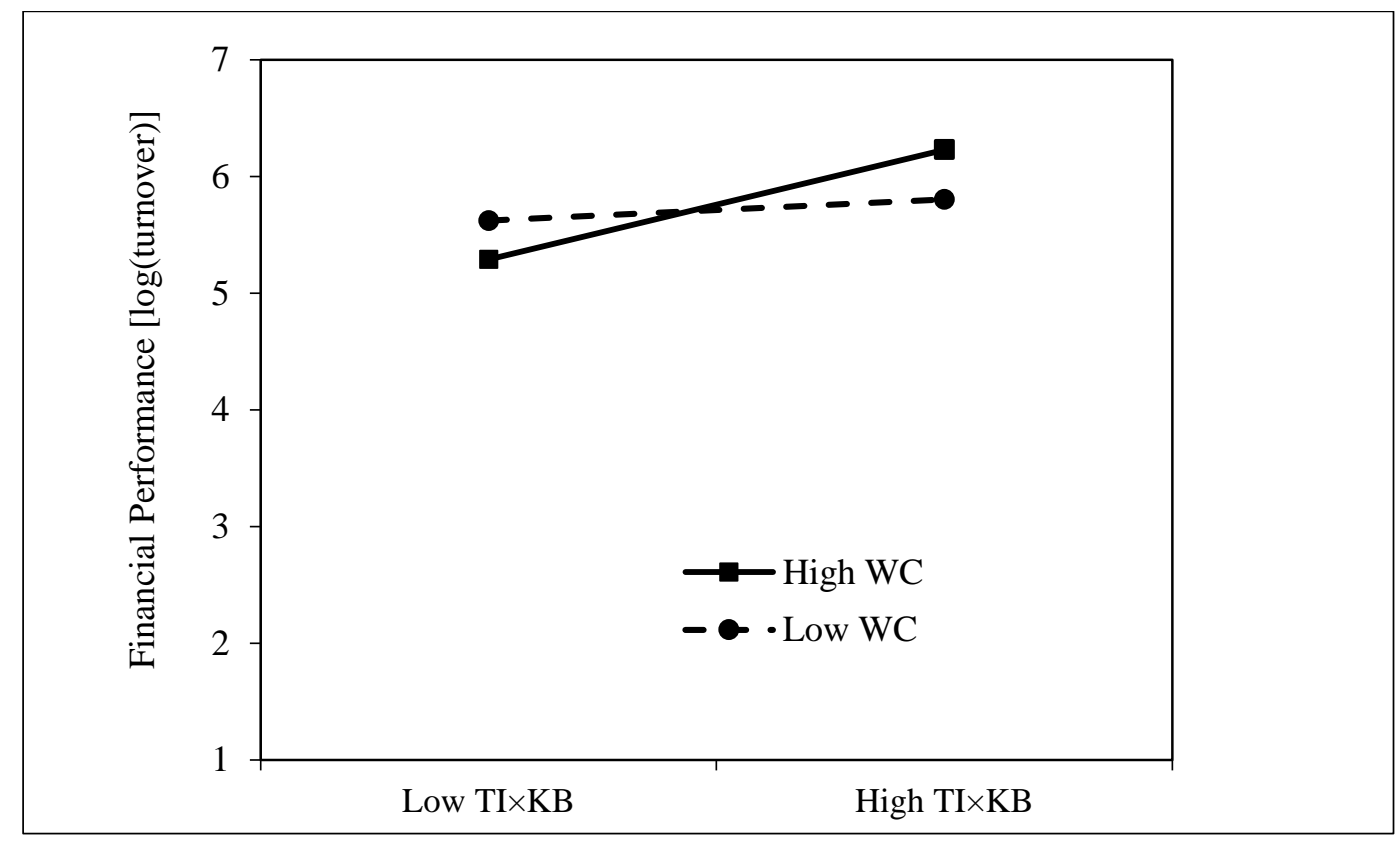

